\title{
EFFECT OF ACUPUNCTURE IN HEART AURICULAR POINT IN TWO INDEXES OF DIGITAL VOLUME PULSE IN HEALTHY SUBJECTS
}

\section{MIGUEL MIZRAIM SERRANO-MORALES ${ }^{1}$, MARCIAL MEJÍA-GONZÁLEZ ${ }^{1}$, MOISÉS SALVADOR CASTAÑEDA-RAMÍREZ², JOSÉ FEDERICO RIVAS-VILCHIS*}

${ }^{1}$ Escuela de Medicina Natural Integrativa, Universidad Evangélica Nicaragüense Martin Luther King (UENIC MLKJr), Campus Mazorca Calpulli A.C., Ciudad de México, México. ${ }^{2}$ Posgrado Especialización en Acupuntura y Fitoterapia, Unidad Iztapalapa, Universidad Autónoma Metropolitana, Ciudad de México, México. Email: jfrv@xanum.uam.mx

Received: 23 January 2020, Revised and Accepted: 12 February 2020

ABSTRACT

Objective: The aim of the study was to determine the changes in two indices derived from the digital volume pulse (DVP) elicited by acupuncture in auricular heart acupoint in healthy subjects.

Methods: Eighteen healthy subjects aged 26.22 2 2.98 years (mean \pm standard deviation) were assigned to receive auricular acupuncture in auricular heart acupoint in the right ear. The DVP was recorded by photoplethysmography. $\mathrm{RI}_{\mathrm{DVP}}$ was determined by the relative amplitudes of systolic and diastolic components of the DVP and $\mathrm{SI}_{\mathrm{DVP}}$, by the relative timing of these components. Auricular acupoint heart was stimulated by manual acupuncture. The $\mathrm{RI}_{\mathrm{DVP}}$ and $\mathrm{SI}_{\mathrm{DVP}}$ indices were calculated for basal and post-acupuncture conditions.

Results: Both $\mathrm{RI}_{\mathrm{DVP}}(\mathrm{p}=0.0375)$ and $\mathrm{SI}_{\mathrm{DVP}}(\mathrm{p}=0.0063)$ were significantly decreased by acupuncture of the right auricular acupoint heart when comparing the pre- and post-acupuncture values.

Conclusions: These results indicate that manual acupuncture of auricular acupoint heart produces acute effects on vascular physiology. $\mathrm{RI}_{\mathrm{DVP}}$ and $\mathrm{SI}_{\mathrm{DVP}}$ indices can be used to assess and demonstrate a vasodilatory activity of auricular acupoint heart.

Keywords: Heart auricular point, Reflection index, Stiffness index, Photoplethysmogram.

(C) 2020 The Authors. Published by Innovare Academic Sciences Pvt Ltd. This is an open access article under the CC BY license (http://creativecommons. org/licenses/by/4. 0/) DOI: http://dx.doi.org/10.22159/ajpcr.2020.v13i4.36917

\section{INTRODUCTION}

Photoplethysmography provides a photoplethysmogram (PPG) or digital volume pulse (DVP), and it is based on the estimation of light transmission through the finger pulp. Changes in the contour of the DVP associated with aging, vascular disease, and drugs have been described $[1,2]$. The shape of the DVP is influenced mainly by the systemic vasculature [3]. Two cardiovascular indices using the DVP, an index of pressure wave reflection $\left(\mathrm{RI}_{\mathrm{DVP}}\right)$ and an index of large artery stiffness $\left(\mathrm{SI}_{\mathrm{DVP}}\right)$, were derived $[4,5]$. Despite the well-recognized effects of auricular acupoints as coadjuvants in the treatment of some cardiovascular disorders, the mechanisms underlying their therapeutic effects remain poorly understood. Nogier described a pulse change when specific auricular acupoints were touched [6]. The detection of this socalled vascular autonomic signal enables the practitioner to precisely determine the location of an acupoint, whether there is a pathology in the region of the body that relates to specific points [7]. Ikezono et al. [8] have demonstrated the existence of an active auricular acupoint and that application of an electric stimulus at this point modifies the radial artery pulse wave. The aim is to examine the acute vascular effects of heart auricular acupuncture point evaluated through $\mathrm{RI}_{\mathrm{DVP}}$ and $\mathrm{SI}_{\mathrm{DVP}}$.

\section{SUBJECTS AND METHODS}

\section{Study design and setting}

This study is designed as an experimental non-randomized singlecenter trial to check if manual acupuncture in heart auricular acupoint modifies de $\mathrm{RI}_{\mathrm{DVP}}$ and $\mathrm{SI}_{\mathrm{DVP}}$ in healthy subjects.

\section{Population}

The study population consisted of 18 healthy male or female (7/9) subjects recruited by advertisement from our medical school with a global mean age of $26.22 \pm 2.98$ (23-32) years.
Ethical aspects

The Research Ethics Committee of the Biological and Health Sciences Division, Iztapalapa Campus, Universidad Autónoma Metropolitana, approved the study, and participants granted informed and written consent.

\section{Acquisition of PPG}

A transducer for photoplethysmograph (MP100, BIOPAC Systems, Goleta, CA, USA) that transmitted infrared light at $860 \pm 90 \mathrm{~nm}$ was placed on the right index finger to obtain the DVP. PPG was recorded through a 12-bit analog-to-digital converter, with a sampling frequency of 200 points/s, and the signal was analyzed with the platform AcqKnowledge v. 3.9 software (BIOPAC Systems, Goleta, CA, USA).

\section{Signal processing and analysis}

The DVP indices of each subject corresponding to basal (60-90 s) and post-acupuncture (300-330 s) periods were calculated using the average of five waves. The first derivative of the DVP was drawn through the Plot graphics analyzer v. 2.6.15 (apps.micw.org, M. Wesemann, Berlin, Germany) to specify inflection points (Fig. 1).

The height of the diastolic peak expressed as a percentage of the amplitude of the systolic peak let calculation of $\mathrm{RI}_{\mathrm{DVP}}$. If no diastolic peak was present, an inflection point was used to extrapolate it. Therefore, diastolic peak was defined as the point at which the first derivative of the waveform was closest to zero, Fig. 1 [9]. $\mathrm{SI}_{\mathrm{DVP}}$ was calculated using subject height $(\mathrm{h})$ divided for $\Delta \mathrm{T}_{\text {DVP }}$, which is the time elapsed between the systolic peak and the diastolic peak/inflection point in the waveform [9], Fig. 2.

\section{Acupuncture treatment}

A physician with 5 years of experience in acupuncture administered acupuncture treatment. We used $1 \mathrm{~cm}$ long and $0.22 \mathrm{~mm}$ wide disposable 


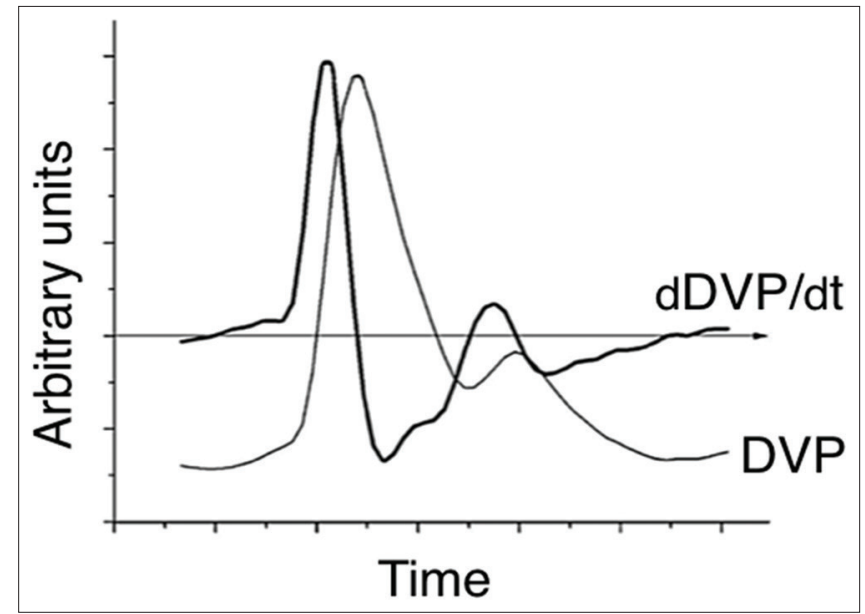

Fig. 1: Digital volume pulse (DVP) recorded by measuring the transmission of infrared light through the finger pulp and its first derivative (dDVP/dt)

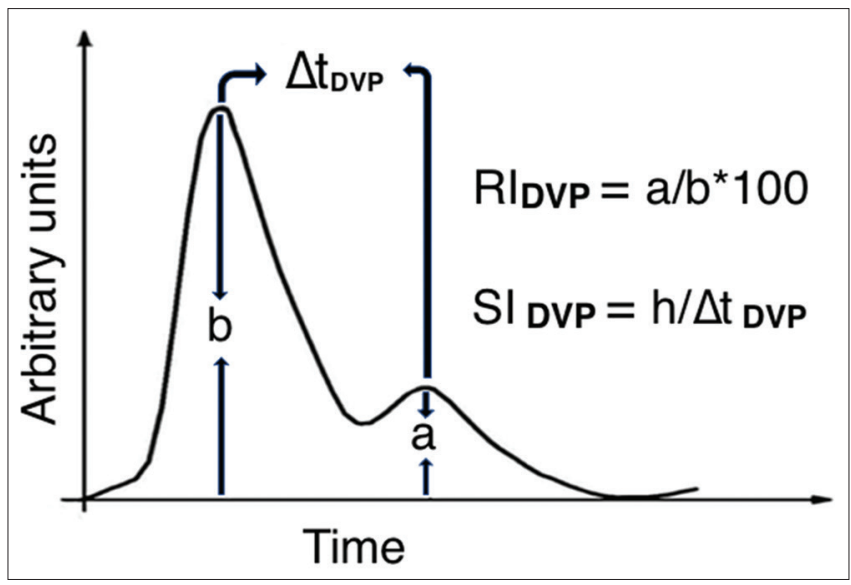

Fig. 2: Calculation of $\mathrm{RI}_{D V P}$ and $\mathrm{SI}_{D V P}$ indices. a: Early diastolic peak. b: Systolic peak. $\Delta t_{D V Y}$ : Time delay between the systolic and diastolic peaks. h: Subject height

stainless steel needles (Hwato, Suzhou, China). The acupuncture needle was manually inserted into the auricular acupoint heart in the right auricle (Fig. 3) without additional electrical or laser stimulation, gently stimulated for $5 \mathrm{~s}$, and needle remained in situ $1 \mathrm{~min}$. Concerning the primary objective of the study, the clinical investigator calculating the DVP indices was blinded respect to if the data belonged to the basal of post-acupuncture period.

\section{Study protocol}

All subjects abstained from caffeine or smoking in the previous $12 \mathrm{~h}$. Measurements were made with subjects in the supine position after a fast night to reach standard conditions and after at least $20 \mathrm{~min}$ rest in a quiet and temperature-controlled clinical room $\left(24 \pm 1^{\circ} \mathrm{C}\right)$. In each subject, a 6 min long registration DVP was obtained. The acupuncture needle was inserted into the heart auricular acupoint in the right ear at $2 \mathrm{~mm}$ deep. The needle was maintained in place for $1 \mathrm{~min}(2-3 \mathrm{~min})$ and removed after that contralateral to the side of the DVP recording.

\section{Statistical analysis}

Data are presented as means \pm standard deviation. Normally distributed continuous variables were compared using Student's t-test. $\mathrm{p}<0.05$ was considered statistically significant. All testing were two sided. Statistical analyses were carried out using the SPSS software v. 21.0 (SPSS Inc., Chicago, IL, USA).

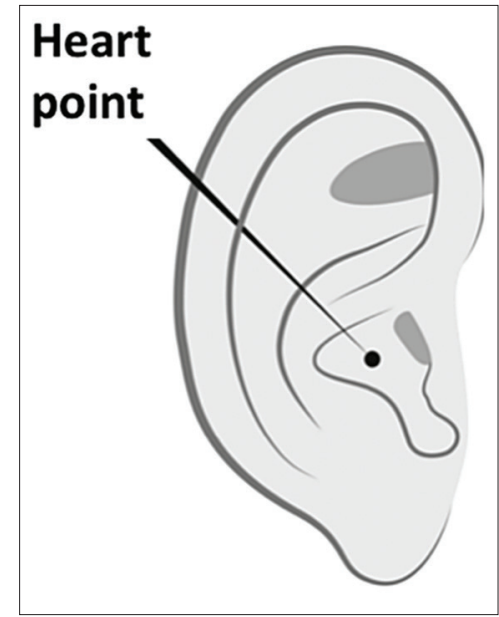

Fig. 3: Heart auricular acupoint

Table 1: Comparison of DVP indices in healthy subjects in the pre- versus post-acupuncture periods

\begin{tabular}{llll}
\hline DVP index & Pre-acupuncture & Post-acupuncture & p-value \\
\hline $\mathrm{RI}_{\text {DVP }}(\%)$ & $68.4 \pm 4.5$ & $60.3 \pm 3.6$ & $0.0375^{*}$ \\
$\mathrm{SI}_{\mathrm{DVP}}(\mathrm{m} / \mathrm{s})$ & $9.14 \pm 2.4$ & $7.67 \pm 2.3$ & $0.0063^{*}$ \\
\hline $\mathrm{RI}_{\text {DVP: }}:$ Reflection index defined as the height of the diastolic peak $(\mathrm{a})$ expressed \\
as a percentage of the amplitude of the systolic peak (b), i.e., $\mathrm{RI}_{\mathrm{DVP}}=\mathrm{a} / \mathrm{b}^{*} 100$. \\
$\mathrm{SI}_{\text {DVP }}:$ Stiffness index defined ash/ $\Delta \mathrm{t}_{\mathrm{DVP}}$ expressed in m/s, and $\Delta \mathrm{t}_{\mathrm{DVP}}$ the time \\
delay between the systolic and diastolic peaks. ${ }^{*} \mathrm{p}<0.05$
\end{tabular}

\section{RESULTS AND DISCUSSION}

Acupuncture in the heart point of the ear elicited the following changes: A significant decrease of the $\mathrm{RI}_{\mathrm{DVP}}(\mathrm{p}=0.0375)$ from the baseline values to those of post-acupuncture and a decrease of $\mathrm{SI}_{\mathrm{DVP}}$ $(p=0.0063)$ when comparing baseline values to post-acupuncture, Table 1.

The effects of vasoactive drugs and nitrates in systemic hemodynamics are assessed through reflection and stiffness indices derived from DVP, such as changes in heart rate and blood pressure [10-12]. $\mathrm{RI}_{\mathrm{DVP}}$ and $\mathrm{SI}_{\mathrm{DVP}}$ have been used to study the mechanisms of acupoints, Rivas-Vilchis et al. [13] showed that manual stimulation of Shenmen and Knee auricular acupoints elicited acute changes in $\mathrm{RI}_{\mathrm{DVP}}$ and $\mathrm{SI}_{\mathrm{DVP}}$.

DVP has a complex but predictable relationship to the aortic pulse pressure. DVP has a direct component arising from pressure waves propagating from the heart to the finger, as well as additional component derived from pressure waves generated in the peripheral arteries, mainly in the lower body, which reflects backward in the arterial system [4]. Therefore, the $\mathrm{RI}_{\mathrm{DVP}}$ index provides a measure of the amount of wave reflection in the systemic circulation [12]. $\mathrm{RI}_{\mathrm{DVP}}$ index is also related to vasodilator stimuli $[14,15]$. Otherwise, $\mathrm{SI}_{\mathrm{DVP}}$ is both associated with the time elapsed between the systolic and diastolic components of DVP and the pulse wave velocity in large arteries and, therefore, reflects large artery stiffness $[4,5,9]$. Hence, the present finding of a decrease in both $\mathrm{RI}_{\mathrm{DVP}}$ and $\mathrm{SI}_{\mathrm{DVP}}$ probably indicated that acupuncture in heart point evoked a vasoactive effect likely related to a vagal response.

\section{CONCLUSIONS}

Our results clearly showed the potential of auricular heart acupoint to modify $\mathrm{RI}_{\mathrm{DVP}}$ and $\mathrm{SI}_{\mathrm{DVP}}$. These indices are valuable in assessing vascular tone and arterial stiffness. The present study has a potential limitation, that is, the unique analysis of the effect of acupuncture on the right ear. Therefore, contour analysis of the DVP can be used to assess the 
cardiovascular outcomes and the related mechanisms of auricular acupoints.

\section{AUTHORS' CONTRIBUTIONS}

MMSM and JFRV contribution includes study design, experiments, and drafted an original manuscript. MMG and MSCR carried out the data analyses and reviewed the drafted manuscript. JFRV elaborated the final version of the manuscript. All authors approved the final version of the manuscript.

\section{CONFLICTS OF INTEREST}

The authors declare no conflicts of interest.

\section{AUTHORS' FUNDING}

The authors received no specific funding for this research project work.

\section{REFERENCES}

1. Dillon JB, Hertzman AB. The form of the volume pulse in the finger pad in health, arteriosclerosis, and hypertension. Am Heart J 1941;21:172-90.

2. Morikawa Y. Characteristic pulse wave caused by organic nitrates. Nature 1967;213:841-42.

3. Nichols WW. Clinical measurement of arterial stiffness obtained from noninvasive pressure waveforms. Am J Hypertens 2005; 18:3S-10.

4. Chowienczyk PJ, Kelly RP, MacCallum H, Millasseau SC, Andersson TL, Gosling RG, et al. Photoplethysmographic assessment of pulse wave reflection: Blunted response to endothelium-dependent beta2-adrenergic vasodilation in Type II diabetes mellitus. J Am Coll Cardiol 1999;34:2007-14.
5. Millasseau SC, Kelly RP, Ritter JM, Chowienczyk PJ. Determination of age-related increases in large artery stiffness by digital pulse contour analysis. Clin Sci (Lond) 2002;103:371-7.

6. Nogier PM. Handbook to Auriculotherapy. Moulins-les-Metz: Maissonneuve; 1981

7. Nogier P. From Auriculotherapy to Auriculomedicine. Saintte-Ruffine, France: Maisonneuve; 1983

8. Ikezono E, Ikezono T, Ackerman J. Establishing the existence of the active stomach point in the auricle utilizing radial artery tonometry. Am J Chin Med 2003;31:285-94.

9. Millasseau SC, Kelly RP, Ritter JM, Chowienczyk PJ. The vascular impact of aging and vasoactive drugs: Comparison of two digital volume pulse measurements. Am J Hypertens 2003;16:467-72.

10. Wagner F, Siefert F, Trenk D, Jäjnchen E. Realtionship between pharmacokinetics and thermodymanic tolerance to isosorbide-5mononitrate. Eur J Clin Pharmacol 1990;38:S53-9.

11. Cardillo C, Kilcoyne CM, Quyyumi AA, Cannon RO III, Panza JA. Decreased vasodilatory response to isoproterenol, during nitric oxide inhibition in humans. Hypertension 1997;30:918-21.

12. Millasseau SC, Ritter JM, Takazawa K, Chowienczyk PJ. Contour analysis of the photoplethysmographic pulse measured at the finger. J Hypertens 2006;24:1449-56.

13. Rivas-Vilchis JF, Cervantes-Reyes JA, Román-Ramos R. Vascular effects of auricular acupuncture evaluated via two digital volume pulse measurement. In: Saad M, editor. Acupuncture: Concepts and Physiology. Rijeka, Croatia: Intech; 2011. p. 27-34.

14. Kelly RP, Millasseau SC, Ritter JM, Chowienczyk PJ. Vasoactive drugs influence aortic augmentation index independently of pulse-wave velocity in healthy men Hypertension 2001;37:1429-33.

15. Stewart AD, Millasseau SC, Kearney MT, Ritter JM, Chowienczyk PJ. Effect of inhibition of basal nitric oxide synthesis on carotid-fermoral pulse wave velocity and augmentation index in humans. Hypertension 2003;42:915-18. 